\title{
CONSIDERAÇÕES SOBRE O IMPOSTO SOBRE SERVIÇOS E COOPERATIVAS DE TRABALHO
}

JOSÉ MENESCAL DE ANDRADE JR.

Especialista em Direito Empresarial pela Universidade Estadual do Ceará. Especialista em Direito Processual pela Universidade Federal do Ceará. Advogado.

jmenescaljr@uol.com.br

\section{FELIPE DOS REIS BARROSO}

Mestre em Administração pela DePaul University (EUA). Especialista em Direito Comercial pela University of Bristol (Reino Unido). Professor da FA7 e da Universidade de Fortaleza. Advogado. felipe.barroso@uol.com.br

Sumário: 1. Das peculiaridades e do funcionamento das sociedades cooperativas; 2. Do funcionamento da cooperativa. Suas peculiaridades; 3. Do princípio da identidade; 4. Da não incidência do ISS sobre as cooperativas; 5. Da ausência de receita e despesas. Da ausência do elemento "preço" que implica em ausência da "base de cálculo"; 6. O enquadramento do ato cooperativo e da atividade da cooperativa de trabalho na regra matriz do ISS; 7. Da ausência do objetivo de lucro no funcionamento da cooperativa; 8. Da ocorrência do bis in idem; 9. Decisões sobre a matéria. Jurisprudência.

Resumo: O presente tema, apesar de não ser exatamente novo, continua atual e na pauta de assuntos polêmicos e de interesse para os estudiosos. Despiciendo falar da carga tributária que beira o confisco no país e que causa insatisfação na sociedade. Ainda mais se se levar em conta o baixíssimo retorno que os administrados têm nos serviços públicos e na infra-estrutura de apoio social. Fosse o retorno mais justo, a carga tributária pareceria mais leve e justa. Neste quadro justifica-se o esforço ingente das sociedades cooperativas para fazer valer os benefícios tributários que a Constituição e as leis lhes 
ensejam e que a fome pantagruélica do poder público pugna por não considerar tais benefícios, sufocando a economia. Em especial, discute-se aqui a não incidência do Imposto sobre Serviços (ISS) sobre a atividade-fim da cooperativa, posicionamento decorrente de disposições normativas, entendimentos doutrinários e farta jurisprudência.

Palavras-chave: Tributos. Cooperativas. Serviços. Não incidência.

\section{DA NATUREZA JURÍDICA DAS COOPERATIVAS DE TRABALHO}

As sociedades cooperativas de trabalho são constituídas sob os ditames da lei federal $\mathrm{n}^{\circ}$ 5.764, de 16.dez.71 (lei de regência das cooperativas), que regula o seu funcionamento. O Código Civil de 2002 trouxe nova regulamentação da matéria, mas não mudou a sua essência, pelo contrário, dispôs expressamente, no seu art. 1.093, que fica ressalvada a norma específica que regula a matéria, ou seja, a lei 5.764/71.

Siqueira (2004), dentre outros doutrinadores, têm considerado que esta lei passou a ter status de lei complementar. Isto por força do art. 146, III, c, da Constituição Federal. Com efeito, esta norma constitucional reserva à lei complementar o adequado tratamento do ato cooperativo. Como a lei 5.764/71 trata da matéria, tomou a feição desta modalidade de norma, nos mesmos moldes do que aconteceu com o Código Tributário Nacional (Baleeiro, apud Siqueira, 2004, p. 27).

A lei de regência das cooperativas ocupou-se em dar os contornos conceituais ao tipo societário, conforme disposto nos seus arts. $3^{\circ}, 4^{\circ}$ e $5^{\circ}$. As cooperativas, na realidade, são sociedades instrumentais auxiliares, voltadas para os seus cooperados. Veja-se a lei, in verbis:

Art. $3^{\circ}$. Celebram contrato de sociedade cooperativa as pessoas que reciprocamente se obrigam a contribuir com bens ou serviços para o exercício de uma atividade econômica, de proveito comum, sem objetivo de lucro.

Art. $4^{\circ}$. As cooperativas são sociedades de pessoas, com forma e natureza jurídica próprias, de natureza civil, não sujeitas a falência, constituídas para prestar serviços aos associados, distinguindo-se das demais sociedades pelas seguintes características:

I. adesão voluntária, com número ilimitado de associados, salvo impossibilidade técnica de prestação de serviços;

II. variabilidade do capital social representado por cotas-partes;

III. limitação do número de cotas-partes do capital para cada associado, facultado, porém, o estabelecimento de critérios de proporcionalidade, se assim for mais adequado para o cumprimento dos objetivos sociais; 
IV. incessibilidade das cotas-partes do capital a terceiros, estranhos à sociedade;

V. singularidade de voto, podendo as cooperativas centrais, federações e confederações de cooperativas, com exceção das que exerçam atividade de crédito, optar pelo critério da proporcionalidade;

VI. "quorum" para o funcionamento e deliberação da assembléia geral baseado no número de associados e não no capital;

VII. retorno das sobras líquidas do exercício, proporcionalmente às operações realizadas pelo associado, salvo deliberação em contrário da assembléia geral;

VIII. indivisibilidade dos fundos de reserva e de assistência técnica educacional e social;

IX. neutralidade política e indiscriminação religiosa, racial e social;

X. prestação de assistência aos associados e, quando previsto nos estatutos, aos empregados da cooperativa;

XI. área de admissão de associados limitada às possibilidades de reunião, controle, operações e prestação de serviços."

\section{Art. $5^{\circ}$ As sociedades cooperativas poderão adotar por objeto qualquer gênero de serviço, operação ou atividade, assegurando- lhes o direito exclusivo e exigindo-se-lhes a obrigação do uso da expressão "cooperativa" em sua denominação. \\ Omissis. (Original sem negrito).}

Assim, a cooperativa é uma sociedades civil, de forma e natureza jurídica próprias, criadas com o fito de prestar serviços aos seus cooperados, sem o intuito de lucro. Ela difere dos outros tipos societários, entre outros aspectos, pelo fato de que:

a) na cooperativa, prevalece o associado e não o capital;

b) não há o intuito de lucro;

c) a finalidade da sociedade é a prestação de serviços direta e desinteressada aos seus cooperados, enquanto na sociedade capitalista a prestação de serviços é o meio de obter o maior lucro possível;

As cooperativas gozam de proteção, estímulo e tratamento especial dispensados pela lei e pela Constituição Federal, que prevê:

Art. $5^{\circ}$. Omissis.

XVIII a criação de associações e, na forma da lei, a de cooperativas independem de autorização, sendo vedada a interferência estatal em seu funcionamento.

Omissis. 
Art. 146. Cabe à lei complementar: omissis

III. estabelecer normas gerais de legislação tributária, especialmente sobre:

omissis

c) adequado tratamento tributário ao ato cooperativo praticado pelas sociedades cooperativas."

Art. 174. Omissis.

omissis

$\S 2^{\circ}$ A lei apoiará e estimulará o cooperativismo e outras formas de associativismo.

Omissis.

\section{Do FunCIONAMENTO DA COOPERATIVA. SuAS PECULIARIDADES}

Conforme a lei e a interpretação mais abalizada da doutrina, a cooperativa tem por objetivo "a congregação dos integrantes de determinada profissão para a sua defesa econômico-social", e "a geração de condições para o exercício das atividades laborais".'É uma sociedade instrumental, que serve para a contratação coletiva dos seus cooperados, evitando-se a exploração do trabalho e eliminando o intermediário na relação.

No desempenho de suas atividades, a cooperativa age como representante de seus cooperados, em relação jurídica similar ao mandato, na medida em que estes, ao ingressarem na sociedade, outorgam poderes a ela para contratar em nome deles. Por sua vez, o ingresso dos cooperados é livre, assim como a sua saída. Em outras palavras, os trabalhadores, desde que satisfaçam as condições e haja condições objetivas de aceitação por parte da cooperativa, podem entrar livremente na sociedade, assim como dela saírem, quando desejarem. É o princípio da porta aberta, consubstanciado no inc. I, do art. 4 , da lei 5.764/71, acima transcrito.

Ressalte-se, ainda, que a atividade é desempenhada sem intuito de lucro, conforme expressa disposição legal contida na parte final do art. 3 , da mesma lei 5.764/71.

No seu funcionamento, a cooperativa repassa aos cooperados os valores que contratualmente recebe dos clientes. Tais valores são repassados na exata proporção da atividade e se constituem em "produção cooperativa".

A atividade é exercida pelos cooperados, que atuam como autônomos, e, como prestadores de serviços, são contribuintes individuais do Imposto sobre Serviços (ISS), ex vi legis.

A cooperativa não presta serviços pertinentes ao campo econômico em que atuam seus cooperados, estes é que o fazem. A cooperativa só presta serviços aos próprios cooperados, serviços estes que se consubstanciam na administração do trabalho individual 
de cada um, assim como todas as atividades voltadas para proporcionar condições de trabalho que, sozinhos, os trabalhadores não teriam condições de obter.

Por tal atividade - ressalte-se - a cooperativa não recebe nada, nenhuma contraprestação. Toda a movimentação é de recursos dos cooperados e em função destes, sem nenhum pagamento à cooperativa, seja a que título for.

O desempenho de tal atividade pela cooperativa consiste na realização do "ato cooperativo", que recebe conceito no art. 79, da lei 5.764/71, in verbis:

Art. 79. Denominam-se atos cooperativos os praticados entre as cooperativas e seus associados, entre estes e aquelas e pelas cooperativas entre si quando associadas, para a consecução dos objetivos sociais.

Parágrafo único. $\mathrm{O}$ ato cooperativo não implica operação de mercado, nem contrato de compra e venda de produtos ou mercadorias.

Assim funciona a cooperativa.

\section{DO PRINCÍPIO DA IDENTIDADE}

Impõe-se considerar que a cooperativa não presta serviços a terceiros e sim aos seus cooperados, que, por sua vez, em seu próprio nome e por sua própria responsabilidade, prestam serviços aos clientes contratados pela sociedade, recolhendo o ISS por tal atividade. Ora, entre a cooperativa e seu associado, consagra a doutrina, que se afigura o princípio da identidade, bem explicado por Lima (1997, p. 51):

A circunstância de ser a cooperativa conceituada como de 'economia auxiliar' ou como 'sociedade auxiliar', posta a serviço do incremento da situação econômica dos seus membros-utentes, levou a doutrina a visualizar na cooperativa uma extensão da economia dos seus sócios, 0 prolongamento, ou o braço alongado das economias associadas. Considerando que o interesse da cooperativa, na prestação do serviço, se identifica com o interesse que o sócio possui em fruí-lo, há escritores que sustentam que as relações entre o cooperado e a cooperativa realizam-se sob a égide do princípio da identidade. O interesse da cooperativa, teoricamente, sempre coincide com o interesse do sócio, na realização dos negócios internos desenvolvidos entre ambos.

Essa identidade de interesses entre a cooperativa e o associado, perceptível nas operações realizadas na esfera das relações internas da sociedade, levou a doutrina a estudar mais detidamente esse negócio interno, nascendo daí a teoria do ato cooperativo. (Original sem grifos e negritos). 
O princípio da identidade é essencial na abordagem da matéria, principalmente levando-se em conta que, no trato do assunto, há que lidar com princípios e conceitos "[...] de um Direito próprio, o Direito Cooperativo." (Bulgarelli, 1998, p. 37).

A propósito do referido princípio, e para compreensão do universo cooperativista, Krueger (2003, p. 58-59), a nosso ver de forma lúcida, traz ilações interessantes e que se afiguram pertinentes:

No caso das cooperativas da maioria dos ramos do cooperativismo, não há ocasião de conflito entre os valores trabalhistas e as regras cooperativistas. Entretanto, pode surgir conflito nas cooperativas de trabalho, já que se está cooperativizando nada menos que o próprio trabalho. Esse é o núcleo do problema. Evidentemente, se no mundo do trabalho protege-se [sic] as crianças, se se aceitam critérios irredutíveis de seguridade, de dignidade humana etc., no âmbito cooperativo não se deve desconsiderar estas regras fundamentais.

Pode-se demonstrar o afirmado a partir da aplicabilidade direta do sistema analítico de Dunlop sobre as relações trabalhistas. O modelo apresenta três protagonistas: os empresários, os trabalhadores e o Estado como legislador ou fiscalizador. Os três protagonistas se interrelacionam e produzem as regras que regem as relações de trabalho, sob a influência das condições ambientais: as condições de mercado, o desenvolvimento tecnológico e a distribuição de poder na sociedade. Ainda os protagonistas agem a partir de certos sistemas de valores que formam suas ideologias.

Entretanto, as cooperativas unificam em um único agente social (protagonista) papéis que as sociedades empresariais em geral separam: são proprietários da cooperativa, ao mesmo tempo em que são provedores ou clientes. Trata-se do princípio da identidade, ou da dupla qualidade que caracteriza o cooperado. Essa dupla qualidade advém do regime autogestionário e auxiliar que caracteriza a cooperativa. A dupla qualidade dos membros da cooperativa explica-se porque esse tipo de sociedade inverte os meios e fins que caracterizam as sociedades empresarias não cooperativas: enquanto nestas, a atividade societária é um meio de alcance dos fins empresariais (lucro), nas cooperativas, as atividades empresariais são o meio de alcance do objetivo societário (acréscimo de renda direto ou indireto) [....]. (Original sem negritos).

O autor, a nosso ver de forma percuciente, vai ao centro da questão, incursionando nas peculiaridades essenciais do sistema de funcionamento das cooperativas, do ponto de vista da visão dos sistemas trabalhista, cooperativista e 
econômico. Mas não é só. Também aprofunda a matéria e mostra a diferença nos pressupostos dos quais partem os sistemas:

A razão primordial das dificuldades de se harmonizar a dupla posição do associado de cooperativa de trabalho como dono e usuário (princípio da dupla qualidade) da cooperativa e de trabalhador na execução de serviços contratados junto à cooperativa consiste no fato de o direito trabalhista e do cooperativismo possuírem lógicas antinômicas. Dessa forma, adotam pressupostos e respostas diferentes ante o mesmo problema: alienação do trabalhador dependente. Como pressuposto, a legislação trabalhista é fruto de uma concepção dialética materialista e histórica. Equivale dizer: tem por seu pressuposto que a relação entre trabalhadores e empresários é intrinsecamente antagônica. O cooperativismo, por outro lado, é fruto de uma concepção utópica de compreensão de uma relação simplesmente oposta (em sentido dual: antagônico e solidário) entre trabalhadores e empresários. [....]

Por sua vez, especificamente no que diz respeito ao ato cooperativo em si, Ataliba ensina:

Atos cooperativos não configuram serviços, em sentido técnico.

Os atos em questão referem-se a relações internas entre cooperativa e cooperado, idênticas às que correlacionam sócios e sociedade, quaisquer que sejam o tipo e natureza. Assim como não se pode falar em serviço tributável em decorrência das relações entre o sócio e a sociedade por quotas de responsabilidade limitada, inviável cogitar de serviço tributável, igualmente, nas relações que enlaçam cooperativa e cooperado.

Nem mesmo no sentido vulgar é correto falar em serviço. Fora diferente e a lei não prestigiaria a expressão "ato cooperativo".

A cogitação de serviço tributável exige a presença do prestador e do tomador. Este, como vimos, é sujeito essencial à figura da prestação de serviços.

Só há prestação de serviços onde haja terceiros.

Cooperado e cooperativa, umbelicalmente, ligados, não são terceiros, um em relação à outra, ou esta em relação àquele.

$\mathrm{O}$ ato cooperativo configura o impropriamente designado, mas expressivo "serviço para si próprio", intributável por excelência porque não há, tecnicamente, serviço para si mesmo. Ausente está o requisito indispensável da presença de outrem, do terceiro destinatário alheio á sociedade. 


\section{(...)}

Tais atos, em suma, são intributáveis posto não configurarem serviço, seja no caso de cooperativas, seja quando atos equivalentes são praticados em qualquer outro tipo de sociedade, civil ou comercial.

As atividades da cooperativa desenvolvem-se no plano interno (negócios-fim) e no plano externo (negócios-meio). As operações no plano interno, onde se situam os atos cooperativos, não envolvem terceiros, pelo que não há prestação de serviços em sentido técnico, nem em sentido usual ou vulgar, porque não há falar-se em prestação de serviços a si mesmo.

É requisito essencial e indispensável para a incidência do ISS a existência do destinatário, do tomador do serviço. A cooperativa e o cooperado não são terceiros nas relações que entre si estabelecem (princípio da identidade). Ao contrário, estão no mesmo pólo em relação aos terceiros, ou seja, às pessoas com quem se relacionam juridicamente. Logo os atos cooperativos não configuram serviços tributáveis.

As operações do plano externo (negócios-meio) - v. conceito acima - são exatamente instrumento, expediente, recurso, meio indispensável para a consecução dos fins societários e também não se constituem obviamente em serviços tributáveis.

\section{DA NÃO INCIDÊNCIA DO ISS SOBRE AS COOPERATIVAS}

Assim, o ISS não incide sobre os serviços que a cooperativa presta porque, em primeiro lugar, só o faz em relação a seus cooperados e, em segundo lugar, nada recebe por esses serviços - caso claro e irrefutável de não incidência tributária.

Corroborando a tese acima, cumpre rever Ataliba:

1. As atividades das cooperativas desdobram-se em dois planos interno e externo.

2. No plano interno situam-se os atos cooperativos que dizem respeito às relações entre cooperativa e cooperados e vice-versa.

3. Essas relações não envolvem terceiros, não havendo, portanto, prestação de serviços, em sentido técnico, nem no vulgar, porque ninguém presta serviços a si mesmo.

4. Requisito ou elemento imprescindível para a incidência do ISS é a existência do destinatário (tomador) do serviço.

5. Sociedade e associado (ou sócio) não são terceiros nas relações que entre si promovem. Ao contrário, situam-se em mesmo polo, em relação às demais pessoas com que se relacionem juridicamente.

6. Logo os atos cooperativos não configuram serviços tributáveis. 
7. As operações externas (ou instrumentais) realizadas pelas cooperativas representam meio para a consecução dos fins societários: a auto-ajuda. Conseqüentemente, também não são traduzíveis em serviços tributáveis.

$[\ldots .$.

17. Por todas estas abundantes razões, podemos afirmar com segurança a impossibilidade jurídica de incidência do ISS sobre o ato cooperativo ou sobre as operações externas das cooperativas. [...]. (Em parecer citado).

\section{DA AUSÊNCIA dE RECEITA E DESPESAS. DA AUSÊNCIA DO ELEMENTO "PREÇO" QUE IMPLICA EM AUSÊNCIA DA "BASE DE CÁLCULO"}

As cooperativas, conforme sua natureza jurídica peculiar e particularidades de seu funcionamento, não têm receita nem despesa, sendo estas dos cooperados. Isso se conclui pelas disposições dos arts. 80 e ss. da dita lei n 5.764/71 e pelas razões de doutrina:

[....] as cooperativas não têm receita e também não têm despesa. Não se trata de mera inexistência de lucro, mas inexistência de receita e despesa, uma vez que a primeira é destinada aos sócios e a segunda é suportada por estes. Ambas proporcionalmente à atividade de cada um." (Lima, 1997, p. 173).

Ainda na linha de raciocínio desenvolvida pelo doutrinador supra, é certo afirmar que as cooperativas só terão receita e despesa quando realizarem atos não cooperativos, ou seja, quando prestarem os serviços, que se constituem no seu fim social, a pessoas da mesma categoria econômica dos sócios, mas que não se incluem no quadro de associados, como já acima referido.

Assim, recebendo valores que são dos seus cooperados e assumindo obrigações e despesas que também são dos seus cooperados, e não auferindo nada em contrapartida pelo exercício de tal atividade, a sociedade não tem receita, nem despesa suas.

Ora, a legislação que regula o ISS prevê que a base de cálculo do ISS é o "preço do serviço".

Tomar-se a receita que é dos cooperados como base de cálculo para a imposição da cobrança do ISS, além de não corresponder à verdade dos fatos na espécie, seria tomar a sociedade cooperativa como sociedade civil comum, tipo societário este em que os sócios trabalham em nome da sociedade. Dislate dessa natureza fere as normas relativas à natureza e organização das cooperativas, o que não pode ser feito pelas normas tributárias. As normas específicas é que dão os conceitos legais, jurídicos dos elementos pertinentes à área por elas reguladas, conforme os arts. 108 a 110 do Código Tributário Nacional. 
Considere-se também que, não tendo receita nem despesa próprias e realizando os serviços sem nada receber por eles, não ocorre o fator "preço", que é elemento essencial e indispensável para ocorrência fática das condições do surgimento da obrigação do pagamento do tributo. Por outra, se a cooperativa nada recebe, o preço dos serviços que presta aos cooperados é "zero" e o percentual da alíquota do ISS sobre zero é zero. O imposto incide, sim, sobre o serviço prestado pelo médico, que já recolhe individualmente o tributo.

Com efeito, conforme já referido, a cooperativa presta aos médicos cooperados os serviços de administração cooperativa da atividade deles (objeto social). A sociedade não presta serviços médicos e hospitalares. Os médicos é que o fazem, com o meio indispensável da rede credenciada, ambos inseridos no ato cooperativo (principal e auxiliar/acessório). Por tais serviços inerentes ao objeto social e dirigidos aos seus próprios cooperados, a cooperativa nada recebe em troca. As despesas de tais serviços (taxa de administração) são despesas dos próprios cooperados retirada de sua própria remuneração, ou seja, de sua produção.

\section{fi O ENQUADRAMENTO DO ATO COOPERATIVO E DA ATIVIDADE DA COOPERATIVA DE TRABALHO NA REGRA MATRIZ DO ISS}

Tem-se mais que, considerando-se não o ato cooperativo em si, na sua contextura jurídica, que, semanticamente (por definição), estaria imediatamente livre da incidência de tributos em geral (art. 79, da lei n. 5.764/71), mas a situação fática que envolve este ato, consistente na prestação de serviço de representação da cooperativa aos seus sócios, a conclusão será no sentido do não preenchimento dos pressupostos da regra matriz, de sorte a não existir o fato jurídico tributário.

Analisando-se o critério de forma tópica, tem-se que: já ficou assentado que os atos das cooperativas de trabalho, no cumprimento de suas finalidades, consistem em organizar e viabilizar a contratação global de seus sócios, ou seja, de praticar o ato cooperativo.

A situação fática resultante do ato cooperativo não gera tributos, pois é realizado sem qualquer fim lucrativo. No caso específico das cooperativas de trabalho, em razão do princípio da dupla qualidade, a ausência de lucro reflete-se na inexistência de receita, como foi exposto acima.

Ao ISS interessa o preço e não o resultado, de sorte que, ao realizar o enquadramento da situação operacional das cooperativas de trabalho na regra matriz do ISS, o intérprete deve observar essa circunstância, especialmente quanto ao conseqüente tributário.

Assim, dentro do já exposto anteriormente, pode-se incluir no critério material da hipótese tributária a prestação de serviço por parte da cooperativa (exclusivamente aos sócios-cooperados), que compreende exclusivamente a representação dos cooperados (médicos prestadores de serviços na área de ação da sociedade e contribuintes 
individuais do ISS para o município) na organização, planejamento e viabilização dos contratos celebrados em nome destes.

Esta prestação realiza-se sempre dentro de um município que tenha exercido a competência de criar o mencionado tributo, com o caráter de não eventualidade, preenchendo-se assim os critérios espacial e temporal da hipótese tributária da regra matriz.

Assim, no critério pessoal, o enquadramento materializa-se com a figuração da municipalidade como sujeito ativo e a cooperativa de trabalho como sujeito passivo. Presentes, pois, os elementos pessoais da relação, permitindo que se processe a verificação do aspecto quantitativo, imprescindível para se completar a relação.

Como já explicado acima, a cooperativa de trabalho nada recebe pela atividade que presta aos seus associados, não possuindo, portanto, qualquer receita própria.

\section{DA AUSÊNCIA DO OBJETIVO DE LUCRO NO FUNCIONAMENTO DA COOPERATIVA}

Como se não bastasse, outro fator também se impõe a favor da conclusão de que as cooperativas de trabalho médico não são devedoras de ISS. É que, como também já frisado, por expressa disposição legal contida na parte final do art. $3^{\circ}$ da lei $\mathrm{n}^{0} 5.764 / 71$, as cooperativas não têm objetivo de lucro, sendo oportuna afirmação de Lima (1997, p. 50):

Como sociedade de pessoas, o destino da cooperativa é servir ao grupo associado, sem a mais leve intenção de lucrar à sua custa [....].

Por definição legal, são tributáveis os serviços que tenham por fim o lucro.

Carvalho, abordando a matéria em parecer sobre ISS e cooperativas afirma:

[....] é lícito asseverar que a hipótese de incidência do ISSQN se consubstancia na prestação a terceiro de utilidades, materiais e imaterias, de conteúdo econômico e com caráter reiterado, sob regime de direito privado, realizada dentro dos limites geográficos do Município, reputando-se acontecido o fato no instante da entrega do serviço, pronto e acabado, à pessoa interessada.

Ataliba, por seu turno, assevera:

[....] sendo as operações instrumentais meios para alcançar um fim que é sempre desinteressado, falta-lhe o conteúdo econômico, suporte inamovível de incidência do ISS, como modelado constitucionalmente. O objetivo de lucro, ainda que potencial, é inafastável para a incidência desse tributo municipal. 
Trata-se de requisito essencial, sem o qual o tributo não pode ser exigido sem afronta à Constituição.

Ora, as cooperativas são entidades sem fins lucrativos, ex vi legis. Logo não se pode submetê-las ao ISS.

Qualquer exigência nesse sentido fere a norma que cuida da estruturação das cooperativas. Mais que isso. Importa incursão no patrimônio privado que a Constituição não autoriza; ao contrário, repele.

Serviço desinteressado é intributável." (In parecer citado, p. 30).

Ora, agindo desinteressadamente para a consecução do seu objetivo social e não recebendo nada por isso, não obtendo "lucro", não há, também por esse motivo, como impingir às cooperativas a obrigação do pagamento do ISS. É pertinente que se diga, ainda, que, às sociedades cooperativas não é vedada a obtenção de resultados positivos ao final de seu exercício social. Tais resultados, previstos na lei de regência, no art. $4^{\circ}$, VII, no entanto, não são "lucro" da cooperativa. São resultados dos cooperados, que, por imposição legal, ficam à disposição da assembléia geral e são primordialmente distribuídos com os associados na proporção de sua produção junto à sociedade, salvo expressa deliberação em contrário da referida assembléia. $\mathrm{Na}$ realidade são recursos dos cooperados, valendo esclarecer que a faculdade de outra destinação deliberada pela assembléia geral consiste na aplicação na própria cooperativa, como, por exemplo, na constituição de um fundo para compra ou construção de imóveis, aquisição de equipamentos, reforma etc., sendo sempre ato em proveito da coletividade dos cooperados. $\mathrm{O}$ retorno das sobras diz respeito à correção do que o cooperado recebe sob a forma de produção durante o exercício.

\section{DA OCORRÊNCIA DO BIS IN IDEM}

Destaque-se outro aspecto relativo ao tópico aqui enfocado. É que, conforme já afirmado, os médicos exercem suas atividades, prestam os serviços que a cooperativa contratou em nome deles, na qualidade de prestadores autônomos.

Em tal situação, são atingidos pela legislação do ISS, que os alcança como devedores do imposto nessa atividade. Assim, os médicos são prestadores autônomos e, ex vi legis, recolhem o ISS sobre tal atividade. Se se admitisse que a cooperativa fosse devedora do mesmo imposto sobre os serviços prestados por seus médicos cooperados, afigurar-se-ia indubitavelmente o bis in idem da exação ou bi-tributação (tomando-se o conceito amplo de bi-tributação como 'toda imposição duplicada de tributo', segundo Moraes, 1973, p. 510-512), o que é rechaçado pela sistemática do ordenamento jurídico tributário nacional. Com efeito, admitindo-se, por hipótese, a obrigação de recolhimento do ISS pela cooperativa, e levando-se em conta que, indubitavelmente, o médico é contribuinte do tributo por essa mesma atividade como 
autônomo, os mesmos serviços seriam tributados uma vez como "receita" da cooperativa, e outra como obrigação pessoal dos médicos cooperados como contribuintes individuais, o que, como visto, é inaceitável no nosso sistema tributário.

\section{DECISÕES SOBRE A MATÉRIA. JURISPRUDÊNCIA}

A matéria já foi objeto de apreciação administrativa, havendo reiteradas decisões favoráveis aos argumentos aqui expostos, dentre as quais destacam-se decisões administrativas das Prefeituras Municipais de Presidente Prudente-SP; Ijuí-RS; Botucatu-SP; Joinvile-SC; Franca-SP; Paranaguá-SC; Salto-SP; Vitória-ES; Petrópolis-RJ; Mogiguaçu-SP; Limeira-SP; Registro-SP; Conselheiro Lafaiete-MG; Cruzeiro-SP; Pato Branco-PR; Santo André-SP, entre outras.

O poder Judiciário, por sua vez, tem prolatado inúmeras decisões judiciais a favor da tese acima exposta. Ressaltem-se, entre outras, as decisões: de primeira instância da Unimed de Porto Alegre-RG, Santos-SP, Pindamonhangaba-SP, Recife-PE, Salvador-BA; decisões de tribunais estaduais: Ceará; Amazonas; Goiás; São Paulo; Pará; Rio Grande do Sul; Rio de Janeiro; Tribunal de Alçada do Paraná;

Há pronunciamento favorável do Superior Tribunal de Justiça (STJ), que decidiu, em votação da Primeira Turma, no recurso especial no $33.260-0$, originário de São Paulo, do qual se destaca trecho do voto do ministro Garcia Vieira (relator):

Processo

REsp 33260 / SP ; RECURSO ESPECIAL

1993/0007659-0

Relator(a)

Ministro GARCIA VIEIRA (1082)

Órgão Julgador

T1 - PRIMEIRA TURMA

Data do Julgamento

$28 / 04 / 1993$

Data da Publicação/Fonte

DJ 07.06.1993 p. 11244

Ementa

ISS - COOPERATIVA MÉDICA SEM FINS LUCRATIVOS.

NÃO ESTÃO OBRIGADOS AO RECOLHIMENTO DO ISS AS

COOPERATIVAS, CONSTITUIDAS PARA PRESTAR SERVIÇOS A SEUS ASSOCIADOS, SEM FINS LUCRATIVOS. 
A CORREÇÃO MONETÁRIA NA REPETIÇÃO DE INDÉBITO É CALCULADA NOS TERMOS DA SUMULA N. 46 DO EXTINTO TFR. RECURSOS IMPROVIDOS.

Acórdão

POR UNANIMIDADE, NEGAR PROVIMENTO AOS RECURSOS.

Referência Legislativa

LEG:FED LEI:005764ANO:1971

ART:00004 ART:0005 ART:00007ART:00003

LEG:FED SUM:000046

O Tribunal de Justiça do Estado do Ceará - TJ-CE já se manifestou favoravelmente sobre a matéria, tendo decidido unanimemente pela procedência da tese aqui esposada, considerando a não incidência do ISS sobre as atividades de uma cooperativa, assim como corroborou o mesmo entendimento em decisão sobre processo que teve como parte a Unimed do Ceará - Federação das Cooperativas de Trabalho Médico do Ceará Ltda. Foram relatores dos dois processos os des. Edgar Carlos Amorim e Edmilson Cruz:

TRIBUNAL DE JUSTIÇADO ESTADO DO CEARÁ-TJ-CE

APELAÇÃO CÍVEL N 96.04084-3

APELANTE: UNIME DE FORTALEZA - COOPERATIVA DE TRABALHO MÉDICO LTDA.

APELADO: MUNICÍPIO DE FORTALEZA

RELATOR: Des. Edgar Carlos Amorim

\section{EMENTA}

$\mathrm{O}$ ato cooperativo tem regime jurídico específico que não enseja a configuração de prestação de serviços em sua feição econômica, sujeita à incidência do ISS.

Não estando na lista federal de serviços a atividade cooperativista, exatamente por não identificar serviço com retribuição, não pode o Município pretender exigir ISS, mesmo que elabore uma lista sua.

Acórdão unânime. 
TRIBUNAL DE JUSTIÇA DO ESTADO DO CEARÁ - TJ-CE

PROCESSO No $95.02187-8$

TIPO DO PROCESSO: APELAÇÃO CÍVEL

COMARCA: FORTALEZA

APELANTE: UNIMED DO CEARÁ - FEDERAÇÃO COOPERATIVA DE TRABALHO MÉDICO DO ESTADO DO CEARÁ

APELADO: MUNICÍPIO DE FORTALEZA

RELATOR: Des. Edmilson Cruz

EMENTA: ISS - COOPERATIVAS - ATIVIDADE EMENENTEMENTE COOPERATIVA - ATO NÃO ABRANGIDO NO CAMPO DE INCIDÊNCIA DO IMPOSTO SOBRE SERVIÇO.

- AMunicipalidade não tem o direito de fazer incidir o referido tributo nas operações realizadas por tais cooperativas - Inteligência dos arts. $3^{\circ}$ e do art. 79 da Lei 5.764/71.

- Ato cooperativo não implica operação de mercado, nem contrato de compra e venda de produto ou mercadoria.

- Ocorrência do bis in idem, por se ter dois serviços distintos, um relacionado com a venda de planos de saúde e assistência médica pela cooperativa, o outro com a prestação de serviço pelo médico filiado à cooperativa.

Recurso conhecido e provido.

Acórdão unânime.

Decisão do STJ tem servido de base para que municípios de todo o país promovam autuações e execuções fiscais contra as cooperativas de trabalho. A principal decisão brandida pelos municípios é a seguinte:

Processo

REsp 254549 / CE ; RECURSO ESPECIAL2000/0033977-6

Relator(a)

Ministro JOSÉ DELGADO (1105)

Órgão Julgador

T1 - PRIMEIRA TURMA 
Data do Julgamento

$17 / 08 / 2000$

Data da Publicação/Fonte

DJ 18.09.2000 p. 105JSTJ vol. 21 p. 117RDDT vol. 63 p. 182RSTJ vol. 139 p. 86

Ementa

\section{TRIBUTÁRIO. ISS. COOPERATIVAS MÉDICAS. INCIDÊNCIA.}

1. As Cooperativas organizadas para fins de prestação de serviçosmédicos praticam, com características diferentes, dois tipos deatos: a) atos cooperados consistentes no exercício de suasatividades em benefício dos seus associados que prestam serviçosmédicos a terceiros; b) atos não cooperados de serviços deadministração a terceiros que adquiram seus planos de saúde.

2. Os primeiros atos, por serem típicos atos cooperados, naexpressão do art. 79, da Lei 5.764, de 16 de dezembro de 1971, estãoisentos de tributação. Os segundos, por não serem atos cooperados,mas simplesmente serviços remunerados prestados a terceiros,sujeitam-se ao pagamento de tributos, conforme determinação do art.87 da Lei 5764/71.

3. As cooperativas de prestação de serviços médicos praticam, naessência, no relacionamento com terceiros, atividades empresariaisde prestação de serviços remunerados.

4. Incidência do ISS sobre os valores recebidos pelas cooperativasmédicas de terceiros, não associados, que optam por adesão aos seusplanos de saúde. Atos não cooperados.

5. Recurso provido.

Acórdão

Vistos, relatados e discutidos estes autos, acordam os Exmos. Srs.Ministros da Primeira Turma do Superior Tribunal de Justiça, porunanimidade, dar provimento ao recurso, nos termos do voto do Exmo.Sr. Ministro Relator. Votaram de acordo com o Relator os Exmos. Srs.Ministros Francisco Falcão, Garcia Vieira e Humberto Gomes deBarros.

Ausente, justificadamente, o Exmo. Sr. Ministro Milton Luiz Pereira.

Com todo respeito ao entendimento considerado no acórdão, entendemos que a decisão parte de premissas falsas e chega a conclusões que discrepam do entendimento doutrinário mais propício ao caso. É que, conforme minudentemente acima exposto, o conceito de ato cooperativo considerado na decisão diverge do conceito doutrinário mais abalizado. Com efeito, no item 1, letras $a$ e $b$ da ementa, há, salvo melhor juízo, impropriedades. Os atos cooperativos têm seu conceito dividido em duas partes: atos 
cooperados em benefício de seus médicos cooperados e atos de administração a terceiros que adquiriram seus planos de saúde. Ora, os atos cooperativos, neste aspecto, são os atos praticados entre a cooperativa e seus associados. Mas naturalmente envolvem terceiros. Não fosse assim, os médicos só praticariam atos cooperativos se se tratassem uns aos outros. Ou por outra, numa cooperativa de táxi, os motoristas só praticariam atos cooperativos se se transportassem uns aos outros. Entrando o terceiro no negócio jurídico, descaracteriza-se o ato cooperativo.

Na realidade, há confusão conceitual nas premissas. Se se considerarem os serviços internos prestados pela cooperativa aos seus cooperados, conforme acima exposto, tem-se que sobre estes não incide o tributo. Se se considerarem os atos que são praticados com envolvimento do usuário, ou seja, do terceiro, não se afigura o ato cooperativo. Os atos, no entanto, se entrelaçam e são, afinal, atos cooperativos que passam ao largo da incidência tributária.

Podemos concluir com os seguintes argumentos:

a) Não incide o ISS sobre a atividade cooperativista de trabalho médico. O ISS não incide sobre os serviços que a cooperativa presta porque, em primeiro lugar, só o faz em relação a seus associados e, em segundo lugar, nada recebe por esses serviços. Caso claro de não incidência tributária ante a inocorrência do fato gerador do tributo, por estar o sujeito passivo fora do alcance da lei tributária.

b) A cooperativa não tem receitas nem despesas (art. 80, da lei 5.764/71). Receitas e despesas são dos cooperados, por expressa disposição legal. A cooperativa presta os serviços aos seus cooperados (na realização do objeto social) desinteressadamente, sem receber nada por isso. O caráter econômico de intuito de lucro é indispensável para a incidência do ISS. Não recebendo nada por isso, não há "preço" de serviço. Não havendo preço não há base de cálculo de ISS, ou se nada recebe pelos serviços aos cooperados, a suposta base de cálculo é zero e a incidência da alíquota sobre zero é zero. Não há incidência.

c) A cooperativa não presta serviços médicos e hospitalares a terceiros (usuários), condição indispensável para a incidência do ISS. Os médicos é que o fazem. A sociedade presta serviços aos seus médicos cooperados, administrando-lhes a atividade e ensejando campo e oportunidades de trabalho.

d) Não se preenchem os pressupostos da regra matriz do ISS, pelo que não ocorre fato jurídico tributário que enseje a obrigação do pagamento do ISS por parte da dita empresa. 
e) Pagamento pela cooperativa seria ocorrência de bis in idem tributário. Os médicos cooperados atuam na qualidade de profissionais autônomos e, nessa situação, recolhem ISS por força de lei. Tributar a atividade do médico como autônomo e a mesma atividade pela cooperativa, que, pelo princípio da identidade, se confunde com o cooperado, seria ensejar a ocorrência do bis in idem tributário, rechaçado pelo ordenamento jurídico tributário brasileiro.

\title{
BibLIOGRAFIA
}

ATALIBA, Geraldo. Parecer: Unimed - Porto Alegre - Sociedade Cooperativa de Serviços Médicos Limitada. São Paulo, 10 nov. 1981.

BULGARELLI, Waldírio. As sociedades cooperativas e sua disciplina jurídica. Rio de Janeiro: Renovar, 1998.

CARVALHO, Paulo de Barros. Parecer: O Imposto Sobre Serviços de Qualquer Natureza e as Cooperativas de Serviços Médicos - pressupostos constitucionais, regramatriz do tributo e peculiaridades que governam sua incidência, para a Unimed do Brasil. São Paulo, s/d.

Krueger, Guilherme (coord.). Cooperativismo e o Novo Código Civil. Belo Horizonte: Mandamentos, 2003.

LIMA, Reginaldo Ferreira. Direito Cooperativo Tributário. 1 ed. São Paulo: Max Limonad, 1997.

MORAES, Bernardo Ribeiro. Curso de Direito Tributário. São Paulo: s/ed, 1973. SIQUEIRA, Paulo César de Andrade. Direito Cooperativo Brasileiro. São Paulo: Dialética, 2004.

\section{SERVICE TAX AND LABOR COOPERATIVES}

\begin{abstract}
The present theme, although it is not totally new, is still polemic and raising special interest of legal experts. It is unecessary to mention the heavy tax burden in Brazil and the high degree of dissatisfaction of society with the low return in terms of social investment. In this context, cooperatives have been demanding the tax benefits brought by the Federal Constitution and collateral norms. Specifically, it is discussed here that labor cooperatives are not subject to service tax, imposed by municipalities throughout Brazil.
\end{abstract}

Key words: Taxes. Cooperatives. Services. Labor. 